\title{
Penerapan Sistem Remunerasi dan Kinerja Pelayanan
}

\author{
Implementation of Remuneration System and Service Performance
}

\author{
Tri Wisesa Soetisna*, Dumilah Ayuningtyas ${ }^{* *}$, Misnaniarti***
}

\begin{abstract}
*Rumah Sakit Jantung dan Pembuluh Darah Harapan Kita, Indonesia, **Departemen Administrasi Kebijakan Kesehatan, Fakultas Kesehatan Masyarakat Universitas Indonesia, Indonesia, ****Fakultas Kesehatan Masyarakat, Universitas Sriwijaya, Indonesia
\end{abstract}

\begin{abstract}
Abstrak
Remunerasi dapat memengaruhi motivasi pegawai sekaligus meningkatkan kinerjanya. Demikian halnya di rumah sakit sebagai institusi pelayanan kesehatan yang padat modal, sumber daya manusia serta padat ilmu dan teknologi. Penelitian ini bertujuan untuk menganalisis persepsi pegawai terhadap implementasi sistem remunerasi dan kinerja unit pelayanan bedah jantung dewasa (UPBJD) di rumah sakit. Penelitian ini menggunakan pendekatan mixed methods (kuantitatif dan kualitatif). Desain penelitian kuantitatif adalah potong lintang menggunakan instrumen kuesioner self-assessment. Sedangkan desain penelitian kualitatif adalah deskriptif, dilakukan melalui focus group discussion dan telaah dokumen pada data berupa buku jadwal, buku registrasi, catatan keperawatan, dan rekam medis. Pengambilan data dilakukan pada tahun 2013 di salah satu rumah sakit di Jakarta. Responden/informan adalah staf medis fungsional, perawat, dan petugas administrasi berjumlah 29 orang. Data dianalisis secara univariat (metode kuantitatif), dan content analysis (metode kualitatif). Hasil penelitian menunjukkan bahwa sebagian besar staf medik fungsional dan perawat tidak puas $(71,2 \%)$ dengan beberapa hal dalam penerapan sistem remunerasi, seperti pada sistem penggajian dan penentuan grading. Terlihat kinerja unit pelayanan bedah jantung dewasa mengalami kenaikan setiap tahun sebelum dan setelah penerapan sistem remunerasi. Diharapkan agar rumah sakit ini dapat memperbaiki sistem remunerasi yang sesuai ketentuan kebijakan dan menyusun formulasi insentif dan bonus yang lebih sesuai dengan kondisi saat ini serta perlu dilakukan sosialisasi yang tepat dan evaluasi secara berkala.
\end{abstract}

Kata kunci: Insentif, kinerja, penilaian diri, remunerasi, rumah sakit

\section{Abstract}

Remuneration can influence worker's motivation and improve their performance. Likewise in hospital as capital-intensive, human resources-intensive as well as knowledge and technology-intensive health care institution. This study aimed to analyze employee's perception of remuneration system implementation and adult cardiac surgery services unit's performance at hospital. This study used a mixed method approach (quantitative and qualitative). Quantitative study design was cross-sectional using questionnaire for self-assesment. Meanwhile, qualitative study design was descriptive conducted through focus group discussion and document review on data in forms of schedule book, registration book, nursing notes and medical records. Data collection was conducted in 2013 at one hospital in Jakarta. Respondents/informants were functional medical staff, nurses, and administration staff amounted to 29 people. Data was analyzed using univariate and content analysis techniques. Results showed most functional medical staff dan nurse were unsatisfied (71.2\%) with several things in remuneration system implementation, such as in payroll system and grading determination. However, adult cardiac surgery services unit's performance is increasing every year before and after the implementation of remuneration system. This hospital is expected to improve the remuneration system in accordance with policy and arrange incentive formulation that is more appropriate with current condition as well as followed with proper socialization and periodical evaluation.

Keywords: Incentive, performance, self-assessment, remuneration, hospital

\section{Pendahuluan}

Rumah sakit, sebagai institusi pelayanan kesehatan bagi masyarakat, merupakan suatu usaha padat modal, padat sumber daya manusia (SDM) serta padat ilmu dan teknologi yang harus mampu mengelola ketiga hal tersebut dengan baik agar dapat menjalankan perannya dengan baik. SDM rumah sakit yang berperan besar dalam pelayanan kesehatan adalah staf medik fungsional (SMF) yang meliputi

Korespondensi: Misnaniarti, Fakultas Kesehatan Masyarakat Universitas Sriwijaya, Kampus FKM Universitas Sriwijaya Ogan Ilir, No. Telp: 0711580068,e-mail:misnaniarti@gmail.com 
dokter umum, dokter spesialis, dan perawat yang memiliki peranan penting dalam menentukan arah kualitas pelayanan kesehatan yang diberikan. Para dokter dan perawat berhak mendapatkan penghasilan atas pelayanan kesehatan yang telah diberikan kepada pasien.

Dalam memberikan pelayanan kepada pasien, tidak dapat dihindari munculnya insentif keuangan untuk dokter dan tenaga kesehatan lainnya. Hal ini terutama terjadi pada sistem pembayaran fee for services. Dalam etika bisnis, pemberian insentif sebaiknya dilakukan berdasarkan kriteria mutu tertentu untuk mencegah terjadinya supply induced demand. ${ }^{1}$ Walaupun sesuai dengan ketentuan peraturan perundang-undangan (Pasal 30 UU Nomor 44 Tahun 2009), rumah sakit berhak menerima imbalan jasa pelayanan serta menentukan remunerasi, insentif, dan penghargaan. ${ }^{2}$ Insentif seharusnya digunakan untuk memengaruhi tenaga kesehatan agar berperilaku dengan baik.

Remunerasi atau kompensasi dapat memengaruhi motivasi pegawai sekaligus meningkatkan kinerjanya. Hal ini disebabkan oleh pemberian remunerasi yang baik dapat memberikan daya tarik pegawai untuk bekerja lebih baik. Kompensasi atau imbalan akan berpengaruh untuk meningkatkan motivasi kerja yang pada akhirnya secara langsung akan meningkatkan kinerja individu. ${ }^{3}$

Rumah Sakit A mulai menerapkan cara pemberian insentif dengan sistem remunerasi kepada seluruh karyawan, termasuk direksi dan dewan pengawasnya pada tahun 2008 berdasarkan Keputusan Menteri Keuangan Nomor 165/KMK.05/2008. ${ }^{4}$ Rumah sakit ini merupakan pilot project pemberlakuan remunerasi pada badan layanan umum milik pemerintah, khususnya rumah sakit milik pemerintah, baik rumah sakit vertikal maupun rumah sakit umum daerah (RSUD). Remunerasi di Rumah Sakit A memiliki konsep dasar remunerasi yang berkeadilan. Konsep tersebut mempertimbangkan pelbagai hal, antara lain struktur gaji yang berdasarkan klasifikasi jabatan dan bobot jabatan (harga jabatan), jenis insentif yang dianggap layak untuk diberikan kepada pegawai negeri sipil (PNS), sistem pemberian insentif yang dikaitkan dengan sistem penilaian kinerja dengan tujuan untuk memacu prestasi dan motivasi kerja. Selain itu, sistem anggaran yang berorientasi kepada kinerja merupakan sistem penganggaran yang memiliki banyak keunggulan positif dibandingkan dengan sistem anggaran tradisional. ${ }^{5}$

Rumah Sakit A telah menghitung dan membayarkan remunerasi pada SMF dengan melihat tiga komponen utama dalam remunerasi, yaitu: pay for people, pay for position, dan pay for performance. Sebelum penerapan sistem remunerasi, sistem penggajian pada SMF di unit pelayanan bedah jantung dewasa dengan mendapat gaji sebagai PNS juga mendapat insentif dengan sistem fee for service. Sedangkan insentif pada kelompok perawat bersifat tetap seperti SDM lainnya. Sebagian SMF melakukan penolakan saat sistem remunerasi akan mulai dilaksanakan karena beranggapan sistem ini dapat mengurangi take home pay sebagian SMF (bedah dan intervensi nonbedah) yang akan terbagi untuk subsidi komponen insentif SDM lainnya di rumah sakit.

Dikhawatirkan ketidakpuasan dari sebagian SMF tersebut akan mengakibatkan turunnya motivasi kerja yang kemudian dapat menurunkan kinerja dan kualitas pelayanan rumah sakit. Disebutkan bahwa pembayaran yang berkeadilan berhubungan dengan pekerjaan, dan pemerataan pada pekerjaan. ${ }^{6}$ Oleh karena itu, tujuan penelitian ini adalah untuk menganalisis persepsi pegawai terhadap implementasi sistem remunerasi dan kinerja unit pelayanan bedah jantung dewasa di rumah sakit setelah sistem remunerasi dilaksanakan. Diharapkan informasi dari penelitian ini bermanfaat dalam memperbaiki penerapan sistem remunerasi di rumah sakit di masa mendatang.

\section{Metode}

Penelitian ini menggunakan pendekatan mixed methods (kuantitatif dan kualitatif). Desain penelitian kuantitatif adalah potong lintang dengan data seluruh variabel dikumpulkan dalam waktu yang bersamaan, sedangkan penelitian kualitatif menggunakan desain deskriptif. Penelitian dilakukan dari Maret sampai Mei tahun 2013 di Unit Pelayanan Bedah Jantung Dewasa di Rumah Sakit A di Jakarta. Populasi penelitian adalah seluruh SMF, perawat, dan petugas administrasi di unit tersebut.

Penelitian kuantitatif menggunakan instrumen kuesioner self-assessment pada 29 orang responden yang terdiri dari SMF, perawat, dan petugas administrasi penjadwalan di unit tersebut. Pemilihan responden berdasarkan kriteria inklusi, yaitu pegawai yang sudah bekerja sebelum tahun 2008 .

Sedangkan metode kualitatif dilakukan melalui focus group discussion (FGD) dan telaah dokumen pada data berupa buku jadwal, buku registrasi, catatan keperawatan, dan rekam medis. Instrumen yang digunakan berupa pedoman FGD, alat pencatat, alat perekam dan dokumen yang ditelaah. Informan FGD terdiri dari SMF dan perawat di Unit Bedah Jantung Dewasa berjumlah 12 orang. Informan tersebut dipilih dengan mengacu pada prinsip kesesuaian karena terkait dengan substansi dan sesuai dengan kebutuhan penelitian.

Pengambilan data penelitian ini terbagi menjadi tiga tahap. Tahap pertama adalah telaah dokumen yang diperoleh dari buku jadwal, buku registrasi, catatan keperawatan, dan rekam medis selama periode tahun 2005 2007 dan 2009 - 2011. Tujuannya untuk melihat kecenderungan jumlah operasi, waktu tunggu pasien sebelum operasi, ejection fraction pasien yang dioperasi, lama perawatan di intensive care unit (ICU), lama perawatan 
pasca bedah, serta pendapatan di unit tersebut. Hasil dari telaah dokumen ini dapat menggambarkan kinerja di unit tersebut sebelum dan setelah diberlakukan remunerasi.

Ejection fraction menurut Cleveland Clinic adalah uji untuk mengetahui seberapa baik jantung dapat memompakan darah setiap berkontraksi. Indikator ejection fraction dapat diukur berdasarkan kemampuan pompa jantung kiri (rongga pompa jantung utama) setiap kontraksi (left ventricle ejection fraction/LVEF) dan pada jantung kanan (right ventricle ejection fraction/RVEF). Namun, pada sebagian besar kasus, yang sering menjadi ukuran adalah LVEF yang dinyatakan dalam persentase. Hasil ejection fraction dapat diklasifikasikan menjadi empat, yaitu $55-70 \%$ kategori normal (baik); $40-55 \%$ kategori di bawah normal (cukup baik); $35-40 \%$ kategori kurang baik; sedangkan $\leq 35 \%$ kategori buruk. $^{7}$

Tahap kedua, dilakukan dengan cara self-assessment menggunakan kuesioner tentang kepuasan terhadap sistem remunerasi kepada seluruh SMF, perawat, dan petugas administrasi penjadwalan di unit pelayanan bedah jantung dewasa. Format kuesioner menggunakan skala Likert rentang pilihan 1 - 4. Skala ini digunakan untuk mengetahui kecenderungan jawaban responden terhadap pertanyaan yang diajukan. Kuesioner terdiri dari 25 pertanyaan meliputi variabel gaji pokok, insentif, tunjangan tetap, fringe benefit, dan prinsip-prinsip remunerasi.

Tahap ketiga pengambilan data menggunakan metode FGD yang terdiri dari satu kelompok dokter dan satu kelompok perawat, masing-masing terdiri dari enam orang. Tujuan FGD ini adalah untuk menggali kedalaman informasi terkait persepsi dan kepuasan terhadap pelaksanaan sistem remunerasi di rumah sakit tersebut.

Pada penelitian ini, dilakukan uji validitas dan reabilitas terhadap kuesioner self-assessment. Pertanyaan dikatakan valid apabila nilai $\mathrm{p}$ (corrected item total correlation) bernilai lebih dari nilai $r$ tabel $(0,514)$. Pertanyaan yang tidak valid akan dibuang dan dilakukan uji ulang. Sedangkan validasi data kualitatif dilakukan dengan triangulasi sumber (menggunakan beberapa kelompok informan yang berbeda), triangulasi metode (menggunakan metode FGD dan telaah dokumen), dan triangulasi data (analisis dilakukan oleh peneliti dan orang yang ahli).

Data kuantitatif diolah dengan bantuan program komputer dan dianalisis secara deskriptif (analisis univariat) untuk melihat distribusi frekuensi dan data tren, sedangkan data hasil FGD dan telaah dokumen dianalisis menggunakan teknik content analysis.

\section{Hasil}

Gambaran Kinerja Unit Pelayanan Bedah Jantung Dewasa

Berdasarkan telaah dokumen, diketahui aktivitas kinerja di unit pelayanan bedah jantung dewasa pada tahun 2005 sampai 2011 (sebelum dan sesudah penerapan remunerasi). Data ini menunjukkan rata-rata jumlah pencapaian kinerja di setiap tahun.

Tabel 1 menunjukkan jumlah operasi terus meningkat setiap tahun, baik sebelum maupun setelah diterapkannya sistem. Diketahui bahwa seluruh capaian telah melampaui target yang ditetapkan dalam Rencana Anggaran dan Belanja (RAB) Rumah Sakit A setiap tahun. Rata-rata waktu tunggu setelah remunerasi lebih panjang dibandingkan sebelum remunerasi, demikian halnya pada lama hari rawat pasien di ICU setelah tahun 2008 cenderung lebih panjang dibandingkan sebelum remunerasi diterapkan.

Lama hari pasca-operasi sebelum dan setelah tahun 2008 cenderung tidak terdapat perubahan. Terlihat angka ejection fraction pasien yang akan dioperasi sebelum dan setelah remunerasi setiap tahun selalu berada di atas $55 \%$. Berdasarkan telaah dokumen, juga diketahui bahwa pendapatan di unit ini cenderung turun sedikit pada tahun 2008, tetapi terus meningkat setelah remunerasi, yaitu meningkat sekitar $33,3 \%$ pada tahun 2009 dibandingkan tahun 2007.

\section{Persepsi terhadap Remunerasi}

Berdasarkan hasil kuesioner, diketahui bahwa setelah penerapan sistem remunerasi, sebagian besar responden $(71,2 \%)$ menyatakan tidak puas (Gambar 1). Ketidakpuasan ini terjadi untuk masing-masing jenis imbalan kerja yaitu gaji PNS, insentif, tunjangan tetap, dan fringe benefit. Masing-masing responden menyatakan ketidakpuasannya mencapai lebih dari $70 \%$ bahkan ada yang mencapai lebih dari $80 \%$. Berdasarkan hal ini, dapat disimpulkan bahwa sistem remunerasi belum berjalan secara tepat sesuai persepsi pegawai.

\section{Remunerasi di Unit Bedah Jantung Dewasa Tahun 2013}

Ketidakpuasan juga terjadi terhadap total nilai insentif yang diterima, dengan alasan kurang sesuai dengan biaya

Tabel 1. Rata-rata Kinerja Pelayanan

\begin{tabular}{lllllll}
\hline \multirow{2}{*}{ Kinerja Pelayanan } & \multicolumn{7}{c}{ Jumlah rata-rata per tahun } \\
\cline { 2 - 7 } & $\mathbf{2 0 0 5}$ & $\mathbf{2 0 0 6}$ & $\mathbf{2 0 0 7}$ & $\mathbf{2 0 0 9}$ & $\mathbf{2 0 1 0}$ & $\mathbf{2 0 1 1}$ \\
\hline Jumlah operasi & 711 & 781 & 942 & 1196 & 1331 & 1473 \\
Waktu tunggu (hari) & 38 & 27 & 48 & 32 & 47 & 47 \\
Ejection fraction (\%) & 56 & 57 & 57 & 58 & 57 & 56 \\
Lama hari pasca-operasi (hari) & 9 & 8 & 8 & 8 & 8 & 7 \\
Lama hari di ICU (hari) & 2 & 2 & 2 & 2 & 3 & 3 \\
\hline
\end{tabular}


hidup saat ini. Walaupun demikian, SMF dan perawat tetap berkomitmen dengan profesinya karena rasa tanggung jawab terhadap pasien yang dihadapinya. Menurut informan berdasarkan hasil FGD, diketahui terdapat kelemahan dan kelebihan dalam penerapan sistem remunerasi (sebelum dan setelah tahun 2008) seperti pada Tabel 2).

Implementasi sistem remunerasi dirasakan banyak memberikan kesempatan kepada dokter junior untuk menambah keterampilan dengan kasus-kasus yang ada. Selain itu, disampaikan bahwa setelah remunerasi berlaku, dibuat peraturan bagi SMF yang masa kerjanya kurang dari lima tahun dikategorikan sebagai dokter monoloyalitas, yaitu tidak diperbolehkan bekerja sebagai dokter paruh waktu di luar Rumah Sakit A. Namun, mereka memiliki hak untuk memperoleh biaya dari rumah sakit untuk mendapatkan pendidikan di dalam dan di luar negeri, asuransi profesi serta pembiayaan kesehatan tambahan selain asuransi kesehatan. Sayangnya, setelah remunerasi pengawasan terhadap ketentuan tersebut tidak berjalan dengan baik. Masih terdapat dokter atau SMF yang berstatus monoloyalitas, namun tetap be-

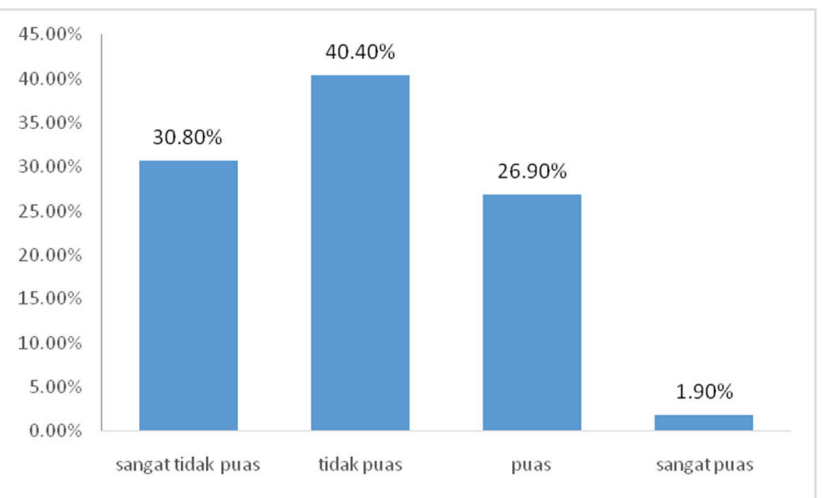

Gambar 1. Proporsi Persepsi Kepuasan Responden terhadap Penerapan Sistem Remunerasi kerja sebagai dokter paruh waktu di luar Rumah Sakit A.

Berdasarkan hasil FGD pada perawat diketahui permasalahan dalam implementasi sistem remunerasi muncul dalam penentuan grading karena dinilai tidak terdapat perbedaan senior dan junior, perawat senior tidak melihat tingkat pendidikan, hanya melihat masa kerja dan beban kerja. Selain itu, perawat merasakan tidak adanya perbedaan mengenai besaran remunerasi antara perawat yang bekerja dengan risiko tinggi (seperti di ICU, CVC, bedah, cath lab) dengan perawat di ruang rawat biasa yang tingkat risiko rendah (average care, poliklinik rawat jalan, dan prevensi rehabilitasi).

\section{Pembahasan}

Berdasarkan hasil penelitian, diketahui bahwa seluruh capaian kinerja melampaui target yang ditetapkan dalam RAB Rumah Sakit A setiap tahun. Jumlah operasi terus meningkat setiap tahun, baik sebelum maupun setelah diterapkan sistem remunerasi. Hal ini selaras dengan studi Norway, ${ }^{8}$ bahwa penerapan sistem remunerasi menyebabkan peningkatan jumlah individu dalam pengawasan dokter gigi serta menurunkan biaya per pasien atau dengan kata lain, dokter dengan sistem remunerasi memiliki produktivitas lebih tinggi dibandingkan dengan dokter yang digaji tetap.

Peningkatan ini dapat terjadi karena jumlah penderita penyakit jantung terus meningkat sesuai data Riset Kesehatan Dasar (Riskesdas) tahun 2013. Berdasarkan data ini, diketahui prevalensi penyakit jantung koroner di Indonesia sebesar $1,5 \%$ atau diperkirakan sekitar 2.650.340 orang. ${ }^{9}$ Sedangkan kematian yang disebabkan oleh penyakit kardiovaskuler sekitar 17,3 juta pada tahun 2008. Diperkirakan angka ini akan terus meningkat mencapai 23,3 juta kematian pada tahun 2030. ${ }^{10}$ Tentunya hal tersebut berdampak kepada Rumah Sakit A yang memili-

Tabel 2. Matriks Kelemahan dan Kelebihan dalam Penerapan Remunerasi Menurut Persepsi Informan SMF

\begin{tabular}{|c|c|c|}
\hline Aspek yang Dinilai & Sebelum Sistem Remunerasi & Setelah Sistem Remunerasi \\
\hline \multirow[t]{5}{*}{ Kelemahan } & $\begin{array}{l}\text { Dokter bekerja mengejar jumlah pasien, karena semakin banyak } \\
\text { pasien semakin banyak pendapatannya (fee for service) }\end{array}$ & $\begin{array}{l}\text { Pendapatan dokter berkurang, dan dinilai tidak sesuai dengan } \\
\text { angka realitas kehidupan saat ini. }\end{array}$ \\
\hline & $\begin{array}{l}\text { Pendapatan dokter per bulan jumlahnya tidak jelas, dan cara } \\
\text { membaginya tergantung kepala unit }\end{array}$ & Aspek kompetensi dokter kurang dihargai \\
\hline & $\begin{array}{l}\text { Terjadi sistem referral, yaitu pasien cenderung berobat ke dokter } \\
\text { yang sudah senior sehingga perkembangan dokter junior menjadi } \\
\text { lambat dan kesulitan mendapatkan fee. }\end{array}$ & $\begin{array}{l}\text { Tidak konsistennya pihak manajemen dalam menerapkan } \\
\text { sistem penilaian }\end{array}$ \\
\hline & Kurangnya transparansi dari faktor pengali $(\mathrm{X})$ & Diterapkannya sistem monoloyalitas di internal rumah sakit \\
\hline & Kurangnya evaluasi & Kurang jelasnya hak-hak pegawai. \\
\hline \multirow[t]{5}{*}{ Kelebihan } & $\begin{array}{l}\text { Kompetensi dokter saat pembagian pasien tidak dihitung sehingga } \\
\text { bagi dokter junior mendapatkan pekerjaan (case) yang lebih seder- } \\
\text { hana sesuai dengan kompetensi yang dimiliki }\end{array}$ & Sistem penggajian lebih transparan \\
\hline & $\begin{array}{l}\text { Penghasilan yang didapatkan lebih tinggi dari pada sesudah } \\
\text { remunerasi diterapkan }\end{array}$ & $\begin{array}{l}\text { Sistem penggajian sudah berdasarkan pendidikan, pelatihan, dan } \\
\text { masa kerja }\end{array}$ \\
\hline & $\begin{array}{l}\text { Adanya penghargaan yang mereka dapatkan walaupun tidak dalam } \\
\text { bentuk uang }\end{array}$ & $\begin{array}{l}\text { Terdapat pemerataan pekerjaan berdasarkan target dan kompe- } \\
\text { tensi untuk mencapai kinerja bersama }\end{array}$ \\
\hline & SMF dapat bekerja di rumah sakit lain sebagai dokter paruh waktu & $\begin{array}{l}\text { Beban pekerjaan yang diberikan sesuai dengan target yang sudah } \\
\text { ditentukan }\end{array}$ \\
\hline & $\begin{array}{l}\text { Adanya kesempatan pembelajaran bagi junior karena pembagian } \\
\text { pasien berdasarkan target unit }\end{array}$ & \\
\hline
\end{tabular}


ki fasilitas dan SDM yang memadai, juga telah dikenal sebagai pusat rujukan nasional untuk penyakit jantung.

Adanya kecenderungan waktu tunggu yang semakin lama sejak remunerasi diterapkan, dapat disebabkan karena pasien yang direncanakan operasi elektif (terencana) terus bertambah banyak setiap tahunnya, sedangkan kapasitas kamar bedah hanya ada tiga dengan SMF bedah hanya lima orang. Kadang-kadang waktu tunggu dapat menjadi lebih lama karena adanya pergeseran daftar tunggu. Pergeseran ini terjadi karena adanya skala prioritas yang lebih tinggi (kegawatdaruratan), atau sebaliknya dapat menjadi lebih cepat karena terdapat pasien yang keluar dari daftar tunggu atas permintaan sendiri dan atau karena pasien mengalami kematian. Penelitian ini memilih waktu tunggu yang ideal berdasarkan The Canadian Cardiovascular Society yaitu $\leq 14$ hari dikarenakan Rumah Sakit A merupakan rumah sakit khusus untuk para pasien penderita kelainan kardiovaskular.

Lama hari rawat pasien di ICU dapat menjadi faktor yang membatasi optimalisasi kamar bedah. Lama rawat pasien juga dapat menunjukkan seberapa efektif tindakan medis dan atau asuhan keperawatan yang diberikan kepada pasien sehingga dapat meningkatkan kondisi pasien, walaupun sebenarnya banyak faktor sebelum tindakan bedah yang dapat memengaruhi keadaan pasien pascabedah, antara lain faktor keadaan sebelum bedah pasien (dilihat dari ejection fraction) dan faktor di luar pasien, yaitu dokter penanggung jawab pelayanan tidak segera memutuskan pasien sudah layak dipindahkan ke tempat perawatan selanjutnya atau tidak.

Pada penelitian ini, rata-rata ejection fraction pasien yang akan dioperasi setiap tahunnya selalu berada di atas 55\% (menurut klasifikasi Cleveland Clinic, ${ }^{7}$ termasuk kategori normal), artinya pasien-pasien yang menjalani operasi dalam kondisi yang baik. Hal ini menunjukkan bahwa pasien-pasien yang menjalani operasi tiga tahun sebelum dan setelah remunerasi dengan kondisi yang baik sehingga bukan menjadi faktor yang memengaruhi lama perawatan pasien pascabedah jantung di unit ini.

Pendapatan di unit ini cenderung meningkat, baik sebelum maupun setelah remunerasi. Hal ini merupakan hal yang positif karena pemerintah memiliki keterbatasan untuk memberikan subsidi rumah sakit ini untuk pemeliharaan dan pengadaaan alat baru sesuai dengan perkembangan dalam bidang kardiovaskular sehingga dengan meningkatnya pendapatan diharapkan dapat memenuhi kebutuhan rumah sakit.

Terkait banyaknya responden yang menyatakan tidak puas dan sangat tidak puas $(71,2 \%)$ terhadap penerapan sistem remunerasi, terutama dalam jenis imbalan kerja, yaitu gaji PNS, insentif, tunjangan tetap, dan fringe benefit. Hal ini mungkin dikarenakan sistem remunerasi yang berjalan tidak sesuai dengan prinsip-prinsip sistem remunerasi berdasarkan Keputusan Menteri Keuangan
Nomor 165 Tahun 2008, yaitu pay for position (jabatan), pay for performance (kinerja, beban kerja), dan pay for people (pendidikan, keahlian, dan kompetensi). ${ }^{4}$

Penyebab lainnya mungkin karena pada saat awal akan dimulainya sistem remunerasi dijanjikan oleh pimpinan rumah sakit bahwa total penerimaan yang akan diterima seluruh SDM rumah sakit tidak akan lebih rendah dari sebelumnya. Namun, yang terjadi adalah sebaliknya, pendapatan SMF invasif sebagai penerima insentif tertinggi di rumah sakit berkurang karena harus memberikan subsidi ke SDM yang lain agar pembayaran remunerasi dapat dilakukan sesuai prinsip yang berkeadilan dan transparan dapat terlaksana baik.

Prinsip tersebut tetap harus dilaksanakan oleh manajemen rumah sakit ini karena ketentuan tersebut diatur dalam Keputusan Menteri Keuangan Nomor 165 Tahun 2008 sehingga tidak dapat dilanggar. ${ }^{4}$ Selanjutnya, SMF yang melakukan tindakan invasif dan telah mencapai tingkat tertinggi dalam kelompoknya tidak akan mendapat insentif yang lebih tinggi lagi. Hal ini terjadi pada semua yang telah mencapai tingkat tertinggi pada kelompoknya masing-masing. Dalam Keputusan Menteri Keuangan tersebut dinyatakan bahwa total remunerasi tertinggi telah ditetapkan, tidak diperbolehkan untuk dilanggar. Sedangkan untuk SMF yang belum mencapai tingkat tertinggi dalam kelompoknya tidak dapat diakomodir untuk mencapai tingkat yang lebih tinggi sesuai kompetensi. Hal itu selaras dengan Siagian, ${ }^{11}$ bahwa salah satu faktor yang memengaruhi sistem imbalan adalah peraturan perundang-undangan. Seperti kasus di Rumah Sakit A ini, sistem remunerasi dijalankan berdasarkan ketentuan Menteri Keuangan.

Timbulnya permasalahan dalam implementasi sistem remunerasi yang dirasakan di unit ini, di antaranya dapat disebabkan karena atasan langsung kurang bisa menyampaikan informasi dengan jelas dan baik serta kurangnya respons dari pihak manajemen terhadap keluhan karyawan tentang remunerasi.

Dapat disimpulkan responden memiliki rasa tidak puas terhadap penerapan sistem remunerasi yang telah berjalan, namun mereka tetap mampu berkinerja baik dan cenderung meningkat setelah sistem remunerasi diterapkan. Menurut teori, banyak faktor yang memengaruhi kepuasan kerja seorang pegawai, antara lain adalah balas jasa yang adil dan layak, penempatan yang tepat sesuai keahlian, berat ringannya pekerjaan, suasana dan lingkungan pekerjaan, peralatan yang menunjang pelaksanaan pekerjaan, sikap pimpinan dalam kepemimpinan, sifat pekerjaan monoton atau tidak. ${ }^{12}$

Faktor lainnya adalah pembayaran seperti gaji atau upah, pekerjaan itu sendiri, promosi pekerjaan, supervisi, dan rekan kerja. ${ }^{13}$ Sedangkan faktor terkuat yang berhubungan dengan kinerja dokter disebutkan adalah karakteristik dokter dan struktur praktik (organisasi). ${ }^{14}$ 
Dikhawatirkan apabila rumah sakit tidak memberikan pendapatan yang memuaskan, maka terdapat kemungkinan dokter akan berpindah ke rumah sakit lain (turnover). ${ }^{1}$ Turnover memiliki dampak yang merugikan bagi organisasi karena dapat menghambat efektivitas dan efisiensi kerja yang selanjutnya akan menurunkan tingkat produktivitas organisasi. ${ }^{15}$

Pemberian remunerasi atau insentif finansial kepada tenaga medis dan paramedis menjadi hal yang penting dalam pelayanan kesehatan. Disebutkan bahwa faktor yang paling berpengaruh dalam penggunaan proses manajemen perawatan (care management processes/ CMPs), salah satunya adalah insentif. Melalui CMPs yang terorganisir dapat meningkatkan kualitas layanan kesehatan pada pasien penyakit kronis sehingga secara tidak langsung, dengan memberikan insentif dapat meningkatkan kualitas layanan kesehatan. ${ }^{16}$

Insentif finansial berupa remunerasi terbukti dapat menghasilkan perubahan aktivitas klinis dokter gigi di pelayanan primer, yang semula cenderung meningkat dengan metode pembayaran fee for services. ${ }^{17}$ Efektif juga dalam mengubah perilaku klinis profesional pelayanan kesehatan, terkait keputusan pencegahan, diagnostik dan pengobatan, atau keduanya. Insentif finansial ini merupakan sumber motivasi ekstrinsik ketika seorang bertindak. ${ }^{18}$

Disebutkan melalui beberapa penelitian bahwa pasien dari dokter yang menerima persentase kompensasi gaji yang lebih tinggi cenderung menerima lima dari tujuh proses pemeriksaan penyakit dibandingkan pasien dari dokter dengan persentase gaji yang lebih rendah walaupun kompensasi tersebut tidak berhubungan langsung dengan proses penanganan pasien tersebut. Tanpa dikontrol model organisasi, diketahui bahwa proses pelayanan kesehatan menjadi lebih baik ketika dokter menerima kompensasi berupa gaji langsung dibandingkan metode fee for services (RR 1,13-1,23) atau sistem kapitasi (RR 1,06 - 1,36). 19, 20

Insentif finansial dapat digunakan untuk mengurangi penggunaan sumber daya kesehatan yang berlebihan, meningkatkan kepatuhan dengan pedoman atau untuk mencapai target program. ${ }^{21}$ Walaupun terkadang metode pembayaran tersebut tidak berpengaruh pada pilihan pelayanan life saving, tetapi pilihan metode pembayaran berpengaruh terhadap keputusan yang diambil dokter dimana dokter merasa jauh lebih terganggu ketika mereka membuat keputusan klinis di bawah metode pembayaran sistem kapitasi (nilai $\mathrm{p}<0,001){ }^{22}$

Insentif finansial juga dianggap sebagai elemen penting dalam mengubah pola resep dokter walaupun dampak kebijakan seperti sistem pay for performance dalam meningkatkan kualitas hasil perawatan dan kesehatan masih belum pasti sehingga perlu penelitian lebih lanjut. ${ }^{23}$

Sama halnya pada dokter pelayanan primer, metode pembayaran berpengaruh pada perilaku pelayanan dok- ter. Dengan metode pembayaran fee for services berdampak lebih banyak kunjungan ke dokter/dokter spesialis dan layanan diagnostik dibandingkan dengan metode pembayaran kapitasi sehingga perubahan dalam pembayaran insentif finansial dapat meningkatkan kualitas pelayanan di pelayanan primer. ${ }^{24,25}$

Dalam penelitian ini, faktor pembayaran atau balas jasa tidak memenuhi kepuasan kerja SMF dan perawat, tetapi mungkin terdapat faktor lain yang dapat membuat mereka puas dan memiliki kinerja baik. Hal ini di antaranya rumah sakit memberikan kesempatan untuk mengembangkan kompetensi dan ilmu pengetahuan, seperti kemudahan melanjutkan pendidikan ke jenjang yang lebih tinggi, mengadakan penelitian, para dokter dapat meningkatkan dan mengasah keterampilannya dengan mengerjakan kasus operasi yang banyak dan beragam serta menumbuhkan lingkungan belajar di tempat kerja.

Menurut Mayo Clinic, 26 penelitian dan pendidikan dianggap penting dalam meningkatan kualitas perawatan terbaik kepada pasien, baik melalui program pendidikan formal dan pelatihan. Rasa tanggung jawab terhadap pekerjaan itu sendiri dan rasa kemanusiaan atau rasa ketertarikan terhadap pasien yang membuat pegawai tetap berkinerja baik.

Selaras dengan penelitian di negara berpenghasilan rendah dan menengah, disebutkan bahwa metode pembayaran berbasis kinerja efeknya tergantung pada interaksi beberapa variabel, seperti besarnya insentif, target dan cara pengukurannya, jumlah dana tambahan, komponen pendukung lain seperti dukungan teknis, dan faktor kontekstual. ${ }^{27}$ Perlu juga dipahami bahwa penerapan sistem remunerasi tidaklah mudah karena isunya sangat kompleks dan akan terdapat konflik pada level korporat tinggi sehingga perlu dukungan dari seluruh pihak, baik pihak manajemen maupun pegawai yang terdapat di organisasi tersebut. ${ }^{28}$

\section{Kesimpulan}

Dapat disimpulkan bahwa mayoritas SMF dan perawat di unit bedah jantung dewasa menyatakan tidak puas $(71,2 \%)$ terhadap penerapan sistem remunerasi, terutama pada aspek total penerimaan remunerasi dan masingmasing komponennya (gaji PNS, insentif, tunjangan tetap, dan fringe benefit). Sebagian besar SMF menyatakan tidak puas terhadap kurangnya peluang untuk naik grading pada kelompoknya, tetapi tidak mengurangi semangat untuk berkinerja secara baik. Diketahui bahwa kinerja di unit ini secara kuantitatif selalu menunjukkan peningkatan setelah sistem remunerasi dilaksanakan, terlihat dari jumlah operasi meningkat sesuai dengan target bahkan ada yang melebihi target, pendapatan cenderung meningkat sesuai dengan penambahan jumlah operasi, rata-rata lama hari rawat pasien ICU, dan rata-rata lama hari pasca-operasi masih sesuai dengan standar. Hanya rata-rata waktu tunggu yang cenderung lebih lama dari sebelumnya. 


\section{Saran}

Diharapkan pihak direksi, dapat melakukan evaluasi yang menyeluruh terhadap sistem remunerasi dengan membentuk tim yang diberikan kewenangan memberikan masukan dan membuat formulasi sistem remunerasi yang akurat dan tepat dengan memperhatikan proporsionalitas, kesetaraan, kepatutan, kinerja dan prinsipprinsip pay for position, pay for performance, pay for people. Perlu diperbaiki sistem komunikasi, kemudian disosialisasikan antara tenaga fungsional dengan manajemen rumah sakit tentang sistem remunerasi serta dilakukan evaluasi secara berkala.

Bagi pegawai, juga sangat penting untuk mempertahankan etos kerja dan kerja sama yang baik, terus meningkatkan kinerja sesuai moto rumah sakit "Patient First", memahami dengan baik peraturan terkait sistem remunerasi dan memberi usulan yang mengakomodasi masukan dari seluruh pegawai dengan memperhatikan prinsip-prinsip sistem yang baik serta memberi masukan tentang sarana dan prasarana yang dibutuhkan untuk lebih meningkatkan kinerja.

\section{Daftar Pustaka}

1. Trisnantoro L. Aspek strategis manajemen rumah sakit antara misi sosial dan tekanan pasar. Yogyakarta: ANDY offset; 2005.

2. Presiden Republik Indonesia. Undang-undang nomor 44 tahun 2009 Tentang Rumah Sakit. Jakarta: Sekretariat Negara Republik Indonesia; 2009.

3. Ilyas Y. Kinerja: teori, penilaian, dan penelitian. Depok: Pusat Kajian Ekonomi Kesehatan FKM Universitas Indonesia; 2002.

4. Keputusan Menteri Keuangan Nomor 165/KMK.05/2008 tentang penetapan remunerasi bagi pejabat pengelola, dewan pengawas, dan pegawai Badan Layanan Umum RSJPDHK. Jakarta: Kementerian Kesehatan Republik Indonesia; 2009.

5. Sulistiadi W. Sitem anggaran rumah sakit yang berorientasi kinerja untuk meningkatkan kualitas keuangan publik. Kesmas: Jurnal Kesehatan Masyarakat Nasional. 2008; 2 (5): 234-40.

6. Gray P. Remuneration, teaching business \& economics. 2007; 11 (1): 13-5.

7. Cleveland-Clinic. Ejection fraction Ohio [online]. Updated 2013 [cited 2013 March]. Available from: http://my.clevelandclinic.org/.

8. Grytten J, Holst D, Skau I. Incentives and remuneration systems in dental services. International Journal of Health Care Finance and Economics. 2009; 9 (3): 259-78.

9. Badan Penelitian dan Pengembangan Kesehatan Kementerian Kesehatan Republik Indonesia. Riset kesehatan dasar tahun 2013. Jakarta: Badan Penelitian dan Pengembangan Kesehatan Kementerian Kesehatan Republik Indonesia; 2013.

10. Kementerian Kesehatan Republik Indonesia. Situasi kesehatan jantung. Jakarta: Pusat Data dan Informasi Kementerian Kesehatan Republik Indonesia; 2014.

11. Siagian SP. Manajemen sumber daya manusia. Edisi kedua. Jakarta: PT Bumi Aksara; 2009.

12. Hasibuan M. Manajemen sumber daya manusia. Jakarta: PT Bumi Aksara; 2007.

13. Umar H. Riset sumber daya manusia dalam organisasi. Jakarta: PT
Gramedia Pustaka Utama; 2000.

14. Dahrouge S, Hogg WE, Russell G, Tuna M, Geneau R, Muldoon LK, et al. Impact of remuneration and organizational factors on completing preventive manoeuvres in primary care practices. Canadian Medical Association Journal. 2012; 184 (2): E135-43.

15. Halimsetiono E. Peningkatan komitmen organisasi untuk menurunkan angka turnover karyawan. Kesmas: Jurnal Kesehatan Masyarakat Nasional. 2014; 8 (8): 339-45.

16. Casalino L, Gillies RR, Shortell SM, Schmittdiel JA, Bodenheimer T, Robinson JC, et al. External incentives, information technology, and organized processes to improve health care quality for patients with chronic diseases. JAMA. 2003; 289 (4): 434-41.

17. Brocklehurst P, Price J, Glenny AM, Tickle M, Birch S, Mertz E, et al. The effect of different methods of remuneration on the behaviour of primary care dentists. The Cochrane Database of Systematic Reviews. 2013; 11: Cd009853.

18. Flodgren G, Eccles MP, Shepperd S, Scott A, Parmelli E, Beyer FR. An overview of reviews evaluating the effectiveness of financial incentives in changing healthcare professional behaviours and patient outcomes. The Cochrane Database of Systematic Reviews. 2011; 7: Cd009255.

19. Ettner SL, Thompson TJ, Stevens MR, Mangione CM, Kim C, Neil Steers W, et al. Are physician reimbursement strategies associated with processes of care and patient satisfaction for patients with diabetes in managed care? health services research. 2006; 41(4 Pt 1): 1221-41.

20. Kim C, Steers WN, Herman WH, Mangione CM, Narayan KM, Ettner SL. Physician compensation from salary and quality of diabetes care. Journal of Generak Internal Medicine. 2007; 22 (4): 448-52.

21. Chaix-Couturier C, Durand-Zaleski I, Jolly D, Durieux P. Effects of financial incentives on medical practice: results from a systematic review of the literature and methodological issues. International Journal for Quality in Health Care. 2000; 12 (2): 133-42.

22. Shen J, Andersen R, Brook R, Kominski G, Albert PS, Wenger N. The effects of payment method on clinical decision-making: physician responses to clinical scenarios. Medicine Care. 2004; 42 (3): 297-302.

23. Rashidian A, Omidvari AH, Vali Y, Sturm H, Oxman AD. Pharmaceutical policies: effects of financial incentives for prescribers. The Cochrane Database of Systematic Reviews. 2015; 8: Cd006731.

24. Gosden T, Forland F, Kristiansen IS, Sutton M, Leese B, Giuffrida A, et al. Capitation, salary, fee-for-service and mixed systems of payment: effects on the behaviour of primary care physicians. The Cochrane Database of Systematic Reviews. 2000; 3: Cd002215.

25. Scott A, Sivey P, Ait Ouakrim D, Willenberg L, Naccarella L, Furler J, et al. The effect of financial incentives on the quality of health care provided by primary care physicians. The Cochrane Database of Systematic Reviews. 2011; 9: Cd008451.

26. Douglas M, Mueller K, Wrenn J. Mayo Clinic: multidisciplinary teamwork, physician-led governance, and patient-centered culture drive world class health care. Commonwealth Fund. 2009; 27 (1306): 1-16.

27. Witter S, Fretheim A, Kessy FL, Lindahl AK. Paying for performance to improve the delivery of health interventions in low- and middle-income countries. The Cochrane Database of Systematic Reviews. 2012; 2: Cd007899.

28. Jensen MC, Murphy KJ, Wruck EG. Remuneration: where we've been, how we got to here, what are the problems, and how to fix them. Massachusetts: The European Corporate Governance Institute; 2004. 